in an amorphous matrix. Recent investigations have shown the presence of an array of about eleven protofibrils, each $20 \AA$ in diameter, inside each microfibril. The results from the X-ray investigations suggest a segmented rope structure for each protofibril in which the strands consist of a succession of short lengths of $\alpha$-helix. The number of strands in the rope is believed to be three.

Another phase of the wool structure programme is concerned with the extraction of proteins from the fibre and their fractionation and characterization. Rupture of the disulphide bonds in wool may be accomplished by performic acid oxidation, sulphitolysis with sodium bisulphite, or oxidative sulphitolysis through the combined action of bisulphite and a mild oxidizing agent. However, thioglycollate reduction and extraction under mildly alkaline conditions is the method most commonly used. Oxidation of the reduced proteins is prevented by treatment with iodoacetate which reacts with the sulphydryl groups. Low-sulphur and high-sulphur protein fractions are obtained from the mixed $S$-carboxymethyl wool proteins. The low-sulphur proteins are believed to come from the microfibrils, and optical rotatory dispersion measurements indicate that they contain 50 per cent $\alpha$-helix. The high-sulphur proteins are believed to come from the matrix and they contain little or no helical protein. Fractionation of the high-sulphur proteins has been moro successful than of the low-sulphur proteins, and two of the high-sulphur protein preparations are believed to be relatively pure. Both contain more cystine, serine, threonine and proline than wool and one is almost devoid of lysine and histidine.

Amino-acid analysis figures strongly in the work of the Division and is used, for example, for following chemical changes in wool and for characterizing wool proteins. In addition to a single column ion-exchange resin automatic machine a nine-column automatic machine has been designed and largely constructed in the Division: it yields nine complete analyses in two days. Methods have been developed of estimating eystine and cysteine in the intact fibre based on amperometric titration, and a radioactive tracer technique is now also available for estimating cysteine in fragments from a single Merino fibre. The estimation of lanthionine in protein hydrolysates has been speeded up and improvements have been made in the method of estimating tryptophan. Determination of acetyl groups in wool indicates that they mask the majority of $N$-terminal groups in the fibre.

Photochemical damage to wool causes yellowing and is produced by ultra-violet radiation from the Sun. Research to develop a method of preventing yellowing has met with partial success and experiments are in hand to determine whether the method is likely to find commercial application. Analysis of yellowed wool reveals partial destruction of tryptophan, tyrosine and cystine, but the chemical nature of the yellow product responsible for the discoloration is not yet known. Research on the photochemistry, chemical reactivity ard structure of wool is supported by investigations on cystine, tryptophan and the other amino-acids of wool, and on synthetic peptides and their derivatives.

The wax sheet method of collecting wool roots developed in the Division in 1948 has enabled the proteins of the roots and the associated enzymes and metabolites to be investigated. Low- and high-sulphur protein fractions can be prepared from wool roots as for the fully keratinized fibre, although the sulphur contents of the fractions aro appreciably lower than the corresponding fractions from wool. Citrulline has been detected in peptide combination in a protein obtained from the inner root sheath. Wool root extracts have been found to contain free aminoacids, all the components of the citric acid cycle, and the enzymes phosphatase (especially pyrophosphatase), aminoacid dehydrogenases, esterase, catalase, transaminase and transpeptidase.

Research on the structure and chemistry of wool and other proteins is already having an impact on the wool industry. Investigations of the hydrothermal shrinkage of collagen and subsequent ease of proteolytic enzyme and bacterial digestion led to the development of a method of digesting sheepskin pieces and damaged, wrinkly or short-wooled skins for the recovery of the wool. The method is now in use in several Australian fellmongeries. Observations on the protection of soluble proteins against damage suggested a commercial procedure for protecting wool against damage during carbonizing. It involves the addition of a certain type of non-ionic wetting agent to the sulphuric acid bath in which the burry wool is soaked before drying and baking. A third illustration of benefits for the wool industry arising from protein investigations is the development of the formic acid dyeing process. This method stemmed from the observation that formic acid has a remarkably good swelling and disaggregating action on the extracted wool proteins. Formic acid solutions of dyes likewise swell the fibre and allow the dye molecules to enter. Swelling is reversed by washing in water but the dye is held in the fibre. The method is now used commercially for printing patterns on wool blankets and its application to top dyeing is boing developed in the C.S.I.R.O. Division of Chemical Engineering.

A number of projects of direct practical importance have been undertaken. It has been found, for example, that the accumulation of wool wax on shearing combs can be prevented by the application of a layer of polytetrafluoroethylene to the lower surface, and the vacuum pressing method of packing wool in a polythene bag before inserting it in the jute bale reduces jute contamination and facilitates handling. The felt moulding process of felting wool to desired patterns in sheets or to three. dimensional articles such as berets and mittens has commercial potential, and the solection, dyeing and tanning of sheepskins for use in hospitals and institutions for tho comfort and protection of patients against the development of bed-sores are increasing in popularity. The boiling of all-wool shrinkproofed hospital blankets in a special detergent to extend their life to three hundred or more laundry cycles is now standard practice in most Australian hospital launderies.

Sharing the resources of the Division between research on the structure and chemistry of wool and on problems of immediate practical importance to the wool industry has produced an interplay of ideas and stimulus that is mutually advantageous to both aspects of the overall programme.
F. G. Lennox

\title{
SCIENTIFIC RESEARCH IN AUSTRALIA
}

$\mathrm{T}$ HE fifteenth annual report of the Commonwealth Scientific and Industrial Research Organization*, covering the year ended June 30,1963 , follows the pattern of recent years. To a general review of the year and a

* Australia: Commonwealth Scientific and Industrial Research Organization. Fifteenth Annual Report, 1962-63. Pp. iv $+162+25$ photographs. (Melbourne: Commonwealth Scientific and Industrial Research Organiza-
tion, 1963.) brief account of significant developments in research, a list of published papers (nearly 50 pages) and lists of members of the Advisory Council, State committees and staff are appended, together with the financial statement. The report is illustrated.

Expenditure during the year amounted to nearly $£ 13$ million, the major items being $£ 1$ million on the National Standards Laboratory, $£ 1 \cdot 35$ million on physical and 
chemical research, $£ 1$ million for biological research of agricultural interest, $£ 1 \cdot 2$ million for regional agricultural research, $£ 971,000$ for industries based on agricultural products, and $£ 800,000$ for work on plant and animal diseases and pests. The $210 \mathrm{ft}$. radio telescope at the National Radio Astronomy Observatory, Parkes, completed its first full year of routine operation; a new field station was established for pastoral research in Western Australia; a Computing Research Section was established to operate the network of computers and carry out basic research in computing and automatic data processing; and the Controlled Environment Research Laboratory, opened in August 1962, was able to provide unique features for growing plants under a wide range of precisely controlled climatic conditions.

Among the features of the year's work noted in the report are the investigations of organic phosphate preparations from soils, which have shown that inositol phosphates are a major component, while phosphorus determination after extraction of soil with ammonium fluoride in hydrochloric acid has been found to give a reliable idea of the need for additional fertilizer. Plant selection work has resulted in a new variety of rice, known as Sircna, which has been released for commercial production to meet the needs of the northern Australian environment; a survey of the effects of nutrient deficiencies has shown that manganese deficiency causes profound changes in chloroplast structure. A wet- and dry-bulb hygrometer has been designed to furnish a tool for transpiration measurements in research on cattle breeding and plant physiology, and 50 per cent reduction of bitter pit in apples has been achieved by spraying with calcium chloride or nitrate.

Blood tests haee been devised for field-tests of the spread of infection in tick-infested cattle in selected environments, and work on drenching sheep with carbon tetrachloride against liver fluke has emphasized the eritical importance of correct drenching procedure. Recent work at Armidale on posthitis in wethers has opened up new possibilities for the prevention and even eradication of the disease from a flock, while a clearer insight into the nature and workings of genetic correlations has been achieved through experimental breeding of Drosophila melanogaster. An association between the proportion of follicles with grossly enlarged outer root sheaves and the severity of crimp deterioration in wool has been confirmed, and the possibility of varying the sulphur concentration in wool at will by dietary procedures has been established. It has also been demonstrated that elimination of copper contamination offers savings in fat losses in ehurning which could represent some $£ 200,000$ to the butter industry. Losses of casein have been greatly reduced and the uniformity of the product improved by a new method of precipitation from skimmed milk; a study of phosphoric acids in organometallie research led to a new method of preparing organic phosphates.

A description of the structure of a liquid or highly compressed gas in terms of a disordered 'tunnel' structure has been developed giving a picture in quantitative agreement with data from X-ray and neutron diffraction and permitting detailed calculations of the ways in which macroscopic properties are determined by the forces between the molecules. From work on the chemical properties of atoms, new methods for studying reaction mechanisms and new processes for making conventional materials have been developed. An investigation of the shapes and time distribution of the light pulses emitted in the early stages of crystallization has provided a new and powerful tool for examining erystallization; in an investigation of fuel-cell reactions a novel process has been developed by which the eatalyst is deposited directly on to the membrane surface by reduction.

Strong evidence has now been obtained that at least some of the amino-end groups of wool and of the highsulphur and low-sulphur proteins of wool are masked by acetyl groups. A number of steroids and fluorene derivatives have been found to possess ice-nucleating properties comparable with those of silver iodide, and $x$-phenazine surpasses silver iodide in this respect. A simple radiometer for measuring both net radiation and its components has been developed and is now being manufactured commercially. To assist the design of large fluidized bed units, an experimental programme is being conducted with fluidized beds of large cross-sectional area; it has been found that in the desalination of sea-water by evaporation addition of very small amounts of polymers of low molecular weight, such as polyacrylic acid, to the sea-water prevents the formation of scale and the tube surface remains remarkably clean for long periods. A laboratory prototype monochrometer suitable for production in Australia has been built and tested and a manufacturing prototype is being developed. Basic investigations of the mechanism by which moisture content changes produce deformation in timber under load indicate very close correspondence between the rate and extent of deformation and the rate and extent of change in moisture content. Road tar with flow properties as good as those of bitumen has been made by adding 10 per cent of coal to the tar before distillation provided moisture is present at the beginning of the distillation; an investigation of the denaturation of egg albumen under acid conditions indicates the presence of a small proportion of a component, $S$-albumin, which is indistinguishable from the remainder except for much greater stability to heat.

\section{SCIENTIFIC RESEARCH IN CANADA}

$\mathrm{T}$ HE forty-sixth annual report of the National Research Council of Canada* covers the year 1962-63, in which tho Council provided financial support for 62 projects involving 44 companies, as well as 10.4 million dollars for research in the universities by way of 1,200 grants and 575 scholarships and 160 fellowships; a further $4 \cdot 3$ million dollars was provided through the Medical Research Council. Some 19,000 technical enquiries from Canadian industries were handled during the year, and the Council now has a scientific research staff of 719 (including 144 post-doctorate Fellows), 952 technical personnel and 845 general service and administrative staff. Of the 10.4 million dollars for university research, $6 \cdot 6$ million dollars $w$ as in grants to individual staff and 1.2 million dollars * The National Research Council of Canada. Forty-sixth Annual Report,
1962-63. Pp. 47. (Ottawa: The National Rosearch Council of Canada, 1963.) for major equipment: the total represents a 20 per cent inerease on 1961-62.

The Division of Applied Biology is studying the lipoproteins of egg-yolk as experimental macromolecular models and also the effects of different immersion cooling methods on the rate and amount of water absorbed by poultry during processing, and the structure and composition of the ribosomes which form the raw material in living cells for muscle, hair, wool, bone and connectivo tissue. Long-range fundamental projects form the bulk of the programme of the Atlantic Regional Laboratory, Halifax. and have included investigations on unusual chemical com. pounds in fungi, mosses, lichens and marine algae, and on the biosynthesis of lignin and ergot alkaloids. Fundamental investigations at the Prairio Regional Laboratory, Saskatoon, have shown that the ergot fungus can be 